\title{
La noción de "texto" de Ricoeur y las funciones de la escritura en las psicosis según Lacan: aproximaciones metodológicas
}

\section{Ricoeur's "text" concept and the functions of Writing in the psychosis according to Lacan: methodological approaches}

\author{
Ignacio IgLEsias ColiLlas \\ UBACyT \\ ignaiglesias@yahoo.com.ar
}

Recibido: 14-02-2012

Aceptado: 15-05-2013

\section{Resumen}

El presente trabajo explora los beneficios metodológicos que la hermenéutica de Ricoeur aporta al psicoanálisis lacaniano en cuanto a la investigación de las funciones de la escritura en las psicosis. Si bien se sabe que los psicóticos en general escriben, los trabajos sobre el tema suelen descuidar los aspectos metodológicos limitando el alcance teórico y práctico de los mismos. No hay en la enseñanza de Lacan un concepto unívoco de "escritura", pero hemos hallado por lo menos tres acepciones del término: la escritura con matemas, la escritura con nudos borromeos y la escritura entendida como cierta precipitación del significante. Dichos resultados son articulados con la noción de "texto" en la hermenéutica de Ricoeur para así fundamentar la pertinencia metodológica del injerto hermenéutico en el psicoanálisis lacaniano -como momento del método- para pensar la escritura en las psicosis.

Palabras clave: escritura, psicosis, metodología, hermenéutica, psicoanálisis lacaniano. 


\begin{abstract}
This paper explores the methodological benefits that Ricoeur's hermeneutics brings to Lacanian psychoanalysis in terms of investigating the functions of writing in psychosis. Although it is known that psychotics usually write, works on the subject often neglect methodological issues limiting the theoretical and practical scope. In lacanian teachings there is not a unitarian concept of "writing", but we have found at least three different meanings of "writing": writing with mathemes, writing with Borromean knots and writing understood as some significant precipitation. These results are linked with the notion of "text" in the hermeneutics of Ricoeur in order to substantiate the relevance of the methodological graft of hermeneutic in the Lacanian psychoanalysis.
\end{abstract}

Keywords: writing, psychosis, methodology, Hermeneutics, Lacanian Psychoanalysis.

\title{
1. Introducción: contextualización y posicionamiento de la problemática
}

El siguiente trabajo presenta algunas reflexiones en torno a la pregunta sobre qué funciones tiene la escritura en la estabilización de las psicosis tal como las entiende Lacan y avanza algunas ideas preliminares sobre la utilidad metodológica que brinda el concepto de "texto" de la hermenéutica de P. Ricoeur para el abordaje de estos interrogantes. Así como Ricoeur planteó en su momento la necesidad de "injertar" la hermenéutica en la fenomenología de Husserl -pasando por la "ontología de la comprensión” de Heidegger1-, propondremos aquí injertar la hermenéutica ricoeuriana en el psicoanálisis lacaniano para esclarecer algunos problemas metodológicos con los cuales nos confrontamos cuando pretendemos estudiar las funciones de la escritura en las psicosis desde una perspectiva psicoanalítica.

El psicoanálisis de las psicosis sigue siendo hoy día un campo de vivos y controversiales debates, y sobre el tema específico al cual quisiéramos abocarnos -las funciones de la escritura en la estabilización de las psicosis- abundan ahora referencias y ensayos de todo tipo, pero se carece - a nuestro criterio- de consistentes definiciones conceptuales que permitan otorgarle a estos trabajos un sólido fundamento teórico, epistemológico y en última instancia clínico, todos ellos términos esenciales para hacer transmisible un saber psicoanalítico coherente y riguroso.

El objetivo fundamental de nuestra tesis general es poder construir herramientas útiles para la intervención clínica, más allá de las necesarias pero a veces impre-

\footnotetext{
1 Ricoeur, P., «Existencia y hermenéutica», en El conflicto de las interpretaciones. Ensayos de hermenéutica, Buenos Aires, Fondo de Cultura Económica, 2003, p. 11.
} 
cisas consideraciones sobre el hecho de que muchos psicóticos "escriben". Por otro lado, muchos trabajos sobre el tema simplemente toman obras literarias o poéticas enteras para buscar en ellas las pruebas, los indicios y detalles que dan cuenta de que el autor en cuestión "era o no era" psicótico.

Ahora bien, ¿cuál es la utilidad de dichos procedimientos? En muchos casos pareciera tratarse de una suerte de constatación circular en la cual el escrito denuncia la psicosis y la obra en sí queda circunscrita y reducida por ese mismo hecho. Estas perspectivas suelen anular en ese mismo movimiento el acontecimiento artístico y la reflexión posible sobre las obras de arte, sean literarias o poéticas, aun habiendo sido escritas por alguien cuya subjetividad puede calificarse de "psicótica"2.

Cabe entonces en este contexto tener algunas precauciones, por ejemplo: ¿a qué fines puede estar siendo funcional -explícita o implícitamente- una operatoria así más que a nuevos pero más sutiles mecanismos defensivos y reificantes del loco que actualizan en las reflexiones sobre su escritura un dispositivo de $\operatorname{control}^{3}$ de su "exterioridad"? 4

En general estos trabajos, fronterizos entre el estudio biográfico, la crítica literaria y el psicoanálisis, descuidan o no consideran la posibilidad de trasladar esos saberes al campo clínico, en el cual se constata que la gran mayoría de los psicóticos distan mucho de ser Schreber, Joyce, Artaud, Hölderlin o cualquier otro célebre personaje. Por otra parte, estos ensayos tampoco abordan la cuestión de la transferencia, concepto fundamental en cualquier investigación que pretenda abrevar en la clínica psicoanalítica.

Habiendo ubicado esta serie de obstáculos que suelen presentar los estudios sobre el tema, nos parece más adecuado plantear algunas preguntas preliminares que proponen un reposicionamiento de los problemas y la apertura de nuevos interrogantes. Dada la complejidad del tema, sería quizás apresurado hacer precipitar cualquier conclusión al respecto.

Que los psicóticos en general escriben es un hecho frecuente y fácilmente constatable; las dificultades y los debates surgen más bien cuando se trata de dirimir el cómo se interpretan y comprenden dichos textos, qué valor se les otorga y en qué contextos y, más importante aún, qué "dicen" esos textos en ausencia del contexto dialogal -diferencia crucial que debería dividir aguas entre aquellos escritos psicóticos producidos en el interior de una relación transferencial con un analista de otros producidos por fuera de una transferencia-.

\footnotetext{
2 Véanse en este sentido las reflexiones de Heidegger sobre Hölderlin en Hölderlin y la esencia de la poesía, Barcelona, Anthropos, 2000.

3 Foucault, M., El poder psiquiátrico, Buenos Aires, Fondo de Cultura Económica, 2005, p. 69.

4 Foucault, M., «La locura, la ausencia de obra», en Historia de la locura en la época clásica, tomo II, Buenos Aires, Breviarios Fondo de cultura Económica, pp. 328-340.
} 
Siguiendo a Ricoeur, esta autonomía del texto -que sanciona como perdidas las intenciones del autor- es algo "constitutivo del fenómeno del texto como escritura" 5 y veremos cómo esta premisa se transforma en un problema insoslayable a los fines de nuestro estudio.

Por supuesto hay muchas otras cuestiones pendientes de ser investigadas pero exceden claramente la finalidad de esta introducción que solo pretende situar en forma panorámica la problemática investigada y esbozar algunas líneas de análisis y reflexión.

\section{Breve sinopsis del proyecto general de investigación}

Dado que en la introducción hemos desplegado un amplio abanico de problemas en relación al tema del ensayo, no podemos dejar de proporcionar una perspectiva panorámica del proyecto general de investigación para así poder localizar con precisión de qué puntos de ese proyecto nos ocuparemos aquí en profundidad, exhibiendo algunos resultados obtenidos en investigaciones anteriores 6 y poniendo en relieve el problema metodológico que articula a Lacan con Ricoeur.

Si bien es desde la obra de Lacan desde donde nos ubicamos teóricamente para definir los conceptos de "psicosis" y "escritura" (y en un momento ulterior del recorrido pretendemos esa misma precisión con el concepto de "transferencia" aplicado a las psicosis), es a partir de la hermenéutica de P. Ricoeur -como adelantábamos en la introducción- desde donde abordaremos el problema metodológico.

En un primer acercamiento, el problema metodológico requiere definir qué se entiende por "texto" y cuáles serán las reglas o premisas con las cuales interpretaremos el valor de los escritos en cuestión, convirtiéndose este movimiento en el paso inmediatamente anterior a la posibilidad de pensar qué funciones subjetivas y de estabilización tendría la escritura en las psicosis.

Aquí se deja entrever un distanciamiento, una no necesaria coincidencia entre la problemática propiamente metodológica y hermenéutica de la noción de "texto" y el valor y función clínica del término "escritura", ampliando -con Lacan- el alcance de esta palabra a un más allá del "acto de escribir", sea este caracterizado como el trazar signos sobre un papel, o sobre una "superficie virtual" cuando se utiliza un procesador de textos por ejemplo; en ambos casos se trata de un "precipita-

\footnotetext{
5 Ricoeur, P., «La función hermenéutica del distanciamiento», en Del texto a la acción. Ensayos de hermenéutica II, Buenos Aires, Fondo de Cultura Económica, 2000, p. 105.

6 Iglesias Colillas, I., «Sobre las funciones de la escritura en las psicosis en el último período de la obra de J. Lacan», en Investigaciones en psicología. Revista del Instituto de Investigaciones de la facultad de Psicología, Año 12, No 2 (2007), Buenos Aires, Ediciones de la Facultad de Psicología de la Universidad de Buenos Aires, pp. 129-137.
} 
do del significante" -tema que desarrollaremos más adelante cuando nos ocupemos de una de las definiciones de "escritura" en Lacan.

Por otra parte, reflexionar sobre la idea de una "superficie virtual" fuerza nuestro recorrido a internarse en el campo de la topología lacaniana y a una reconsideración del concepto de "inconsciente", problemas que están íntimamente ligados a la lógica subjetiva del psicótico - especialmente en lo referido a su corporalidad-y a las posibles funciones de la escritura en cuanto a lo estrictamente clínico.

Sintetizando, nos enfrentamos entonces a tres grandes ciclos de problemas:

1. Problemas operacionales: el cómo definir en términos operacionalmente adecuados los siguientes términos:
a) Escritura
b) Psicosis:
- esquizofrenia
- paranoia
- psicosis maníaco-depresiva
c) Función

2. Problemas metodológicos: con qué noción de "texto" y con qué reglas de interpretación reflexionaremos sobre los escritos que tomemos en consideración, siendo este un problema propiamente hermenéutico.

3. Problemas clínicos: habiendo definido y localizado los conceptos mínimos requeridos por los problemas operacionales y metodológicos, podemos pasar a interrogar el problema de la "transferencia" en las psicosis y el valor y funciones clínicas que la escritura podría tener en el no desencadenamiento, estabilización o simple alivio momentáneo del padecimiento.

En este trabajo nos ocuparemos exclusivamente de la definición operacional del término "escritura", es decir del punto "1. a)" y de los problemas metodológicos, esto es el punto 2 del esquema propuesto. Esta decisión metodológica es entonces el resultado de haber dejado de lado cualquier posibilidad de "psicoanálisis biográfico" de algún sujeto psicótico como leit motiv del proyecto, cualquier "estudio estético" que imbrique la escritura con la psicosis, así como también del rechazo a generalizar -ya en la formulación misma del problema- la idea de que se puede hablar de "la" psicosis como si tratara de un campo homogéneo de fenómenos y lógicas subjetivas.

Aquí la hipótesis auxiliar es que la escritura tendría diversas funciones subjetivas en las distintas grandes formas clínicas de las psicosis: paranoia, esquizofrenia y psicosis maníaco-depresiva.

Detengámonos entonces en algunas definiciones de escritura aisladas en la obra de Lacan, especialmente en su último período que va del año 1974 a 1981. 


\section{Las definiciones de escritura en la obra de Lacan}

En el camino hacia nuestro objetivo principal que era explorar y determinar qué función adjudica Lacan a la escritura en la estabilización de las psicosis hemos encontrado que no había en la obra lacaniana una definición unívoca de "escritura" y que, en rigor, tampoco se aludía en ella a la "estabilización" de las psicosis tanto como a su suplencia, es decir a aquellos procedimientos relacionados con la escritura que evitan que ella se desencadene.

El caso paradigmático para pensar esto último es el seminario 23 de Lacan, «El sinthôme», dedicado casi exclusivamente a Joyce y su obra ${ }^{7}$. Precisamente, si la tesis lacaniana sobre la lógica subjetiva psicótica de Joyce era acertada, Joyce jamás desencadena una psicosis clínica de pleno derecho; esto no quiere decir que a partir de ciertos fenómenos discursivos -especialmente a partir de los aspectos formales de su escritura- no se pueda ubicar dicha lógica de funcionamiento, en ausencia de la psicosis clínica.

Lacan hace referencia a la escritura al menos en tres acepciones que conviene distinguir pero que no son absolutamente separables:

1) la escritura en matemas entendiendo a la lógica como ciencia de lo Real, es decir, los matemas como fórmulas escritas - como en las matemáticas- que carecen de sentido en sí mismas, y la respectiva reelaboración del concepto de "Inconsciente";

2) la escritura con nudos borromeos entendida como "un hacer que da soporte al pensamiento" $\mathrm{y}$,

3) la escritura entendida como cierta precipitación del significante, el acto de escribir sobre una superficie.

Despleguemos entonces cada una de ellas.

1) La escritura en matemas: la lógica como ciencia de lo Real, lo Inconsciente como sedimento del goce.

Comencemos analizando la primera acepción: la escritura en matemas. A lo largo de toda su obra, de principio a fin, Lacan hace un esfuerzo considerable por abrir, reabrir o fundar un diálogo explícito entre el psicoanálisis y la filosofía ${ }^{8}$, así como también con las ciencias humanas en general -antropología, lingüística, etc.y también con las ciencias "duras" -la matemática y la física, por ejemplo-. La intención fundamental era lograr escribir un saber transmisible propio del psicoaná-

\footnotetext{
7 Lacan, J., El sinthome (1976-77) [seminario, libro 23], Paidós, 2006.

8 Véase en este sentido el libro de Juranville, A., Lacan y la filosofía, Buenos Aires, Nueva Visión, 1992.
} 
lisis, utilizando el formato del matema o fórmula, que en sí misma carece de significación en tanto escritura de letras.

Aproximadamente a partir del seminario 209 (1972-73) y apoyándose en la conceptualización de los tres registros -Real, Simbólico e Imaginario- Lacan sostiene que la lógica es por excelencia la ciencia de lo Real.

Siendo que los tres registros son tres dimensiones del dicho, ${ }^{10}$ lo Real en este período de su enseñanza es entendido -siguiendo entre otras a la lógica modal aristotélica- como todo aquello que "no cesa de no escribirse", como lo imposible en términos lógicos, pero también como aquellas letras que la lógica se ocupa de vaciar de sentidos subjetivos para escribir proposiciones.

Esto lleva a Lacan a decir que la formalización de la lógica matemática se sostiene en lo escrito11. Por otro lado afirma que "el inconsciente y la lógica son del orden de lo escrito"12, como paso previo a poder sostener que lo inconsciente puede ser conceptualizado a partir de fórmulas lógicas, es decir vía los matemas. En este sentido la importancia del escrito es cómo la escritura misma del álgebra de las letras "R.S.I." terminan designando las tres dimensiones del espacio del ser hablante y que en tanto categorías son estrictamente equivalentes. Se pretende así resaltar la dimensión de lo Real -habiendo hecho hincapié durante años en "lo Simbólico"-, "advertir lo que hay de Real en lo Simbólico"13.

Hay que aclarar también que este espacio del ser hablante no es el espacio tridimensional tal como lo piensa la geometría euclidiana, sino que se trata del espacio del lenguaje. Cuando Lacan afirma que "el inconsciente está estructurado como un lenguaje"14, o más bien, si se lee este axioma a partir de los textos de la década de los años setenta, se puede sostener que más que un reduccionismo del Inconsciente al lenguaje -crítica a nuestro criterio carente de fundamento- de lo que se trata es de pensar que lo Inconsciente, al igual que el lenguaje -de ahí que diga "estructurado como un lenguaje"- no está ni adentro ni afuera; Sujeto y Significante son términos a ser pensados en un espacio topológico.

Esto no es de ningún modo una innovación lacaniana, sino que podemos encontrarla en Freud cuando afirma en «Más allá del principio de placer» (1920) que el genuino objeto de estudio del psicoanálisis es la neurosis de transferencia ${ }^{15}$, es decir

\footnotetext{
9 Lacan, J., Aún (1972-73) [seminario, libro 20], Buenos Aires, Paidós, 2001.

10 Lacan, J., «El atolondrado, el atolondradicho o las vueltas dichas» (1972), en Escansión 1, Buenos Aires, Paidós, 1984.

11 Lacan 2001, op. cit., (nota 9), p. 112.

12 Lacan, J., Los nombres del padre o Los no incautos yerran (1974-75) [seminario, libro 21], inédito, p. 89.

13 Ibídem, p. 8.

14 Lacan, J., La ética del psicoanálisis (1959-60) [seminario, libro 7], Buenos Aires, Paidós, 2003.

15 Freud, S., «Más allá del principio de placer» (1920), en Obras Completas, tomo XVIII, Buenos Aires, Amorrortu, p. 51.
} 
un fenómeno que se produce "entre" paciente y analista, antecedente conceptual de lo que luego Winnicott denominó "espacio transicional"16. Estos desarrollos -especial y explícitamente los lacanianos- permiten superar algo que en Freud permanece como antinomia: el impasse entre la "realidad psíquica" y la "realidad material"17 (eliminando la dicotomía "interior - exterior").

Como se podrá notar, los conceptos de "Inconsciente" y de "escritura" se van redefiniendo en simultáneo, produciéndose alteraciones mutuas y bidireccionales.

El autor afirma también que "el saber en tanto que inconsciente (...) quiere decir que es un Real (...). Es un depósito. Es un sedimento que se produce en cada uno cuando comienza a abordar esa relación sexual a la que por cierto no llegará nunca"18. Esta noción de Inconsciente en tanto saber-depósito y en tanto sedimento cobra toda su relevancia para pensar las funciones de la escritura en las psicosis, pero para extraer las debidas consecuencias debemos aún seguir precisando las nociones de "escritura".

En este punto preciso -siguiendo lo expuesto al inicio de esta primera acepción de "escritura"- volvemos a encontrar un punto homólogo entre Inconsciente y matemas: se alude a "esa reducción a las dimensiones de la superficie que exige lo escrito (...). Por eso no creo vano haber llegado, al cabo, a la escritura del $a$, del $\$$, del significante, del $A$ y del $\Phi$. Su escritura misma constituye un soporte que va allende la palabra, sin salir de los efectos mismos del lenguaje. Tiene el valor de centrar lo simbólico, con la condición de saber usarla (...)"19.

El saber inconsciente que se inventa en el análisis -Lacan ha abandonado a esta altura la idea de que lo inconsciente "ya estaba ahí en algún lado" y el análisis simplemente "lo descubre"-, al mismo tiempo que se inventa, se escribe. Esto retoma los desarrollos del escrito de 1957 denominado «La instancia de la letra en el inconsciente o la razón desde Freud». En este escrito se designaba como letra "ese soporte material que el discurso concreto toma del lenguaje" 20 y como "la estructura esencialmente localizada del significante" 21 .

En este contexto, la pregunta que asedia al concepto de «letra» es la siguiente: ¿dónde se sitúa la escritura? Se puede deducir rápidamente que Lacan está haciendo referencia al psicoanálisis de las neurosis, y es en estos puntos donde faltan aún grandes desarrollos para repensar estos conceptos en el campo de las psicosis. Sí está claro que tanto en la referencia del seminario 21 (1974-75) como en la de «La

\footnotetext{
16 Winnicott, D., «Objetos transicionales y fenómenos transicionales», en Realidad y juego, Barcelona, Gedisa, 2001, pp. 17-45.

17 Lacan 1974-75, op. cit. (nota 11), p. 7.

18 Ibídem, p. 88.

19 Lacan 2001, op. cit. (nota 10), pp. 112-113.

${ }^{20}$ Lacan, J. «La instancia de la letra en el inconsciente o la razón desde Freud» (1957), en Escritos 1, Buenos Aires, Siglo XXI, 1988, p. 475.

21 Ibidem, p. 481.
} 
instancia de la letra...» (1957) la "escritura" hace referencia al "centrar lo Simbólico" y a la "localización del significante".

Ahora bien, repasando lo dicho hasta aquí, esta breve secuencia viene bordeando una y otra vez el registro de lo Real; pero habíamos afirmado -siguiendo a Lacan-que lo Real es "lo imposible", y podemos agregar que es lo imposible de ser pensado sin el entrometimiento de lo Simbólico, o, lo que es lo mismo: "no hay la menor esperanza de alcanzar lo Real por la representación" 22 . Ergo, lo Real se inventa a partir de lo Simbólico 23 .

Si esto es así, tiene que existir entonces un concepto que anude los tres registros -Real, Simbólico e Imaginario, que recordemos que son las dimensiones del ser hablante-, y a ese concepto Lacan lo denomina "objeto a". Si el "objeto a" tiene como función primordial anudar los tres registros -tanto es así que cuando Lacan recurre a los nudos borromeos para pensar la experiencia del análisis lo escribe en el punto de calce de los tres redondeles de cuerda-, es lógico sostener que dicho objeto tenga también "tres caras" o aristas, una Real, otra Simbólica, y otra Imaginaria.

En este momento de la argumentación, se recurre a un concepto paradigmático del anudamiento entre lo Real y lo Simbólico: el concepto denominado "Significante - Uno" (S1). La particularidad de este "Significante - Uno" es que se trata de un "significante - letra (...), significante que sólo se escribe porque se escribe sin ningún efecto de sentido. Homólogo, en suma (...) del objeto a"24.

Señalemos al menos rápidamente que el "objeto a" refiere conceptualmente y en primera instancia a lo que Freud denominaba satisfacción pulsional y a lo que no entra en el campo de las representaciones, es decir a lo Real. En Lacan encontramos una reelaboración sumamente compleja y novedosa que incluye pensar la satisfacción pulsional con el concepto denominado "goce", sólo que "goce" es un concepto un tanto más amplio, que no se reduce exclusivamente a la satisfacción pulsional freudiana.

Este "Significante - Uno" (S1), este "significante - unidad es capital (...). Lo único que está al alcance de la mano es la letra" 25 -sostiene Lacan-. En este contexto Lacan se compara con Aristóteles diciendo que "cuando uno se propone dar una idea del elemento, tiene que valerse de una serie de letras, ro, sigma, tau, exactamente igual que nosotros" 26 . Queda abierto así el camino para sostener que es únicamente a partir de la "letra" que tenemos acceso a lo Real27.

22 Lacan, J., «La tercera» (1974), en Intervenciones y textos 2, Buenos Aires, Manantial, 1998, p. 82.

23 Rabant, C., Inventar lo Real. La desestimación entre perversión y psicosis, Buenos Aires, Nueva Visión, 1993.

24 Lacan 1998, op. cit. (nota 21), p. 83.

25 Ibidem, p. 95.

26 Ibídem.

27 Ibídem, p. 106. 
Parece entonces que "escritura", "letra" y "objeto a" son conceptos que mantienen íntimas relaciones. El "objeto a" presenta en este sentido dos caras: por un lado, el "objeto a" es algo con lo cuál el hombre imagina, imagina algo que no existe pero que tiene toda su potencia en la subjetividad ya que la distribución de los goces es lo determinante en la lógica subjetiva: "se imagina con lo que se puede, a saber, con lo que se chupa, lo que se caga, lo que hace la mirada (...) y (...) la voz"28.

Por otro lado, la otra cara del "objeto a" es "una cara que es tan Real como resulte posible, sólo por el hecho de que se escribe. Ven lo que trato de hacer-sigue Lacan-: trato de situarles lo escrito como ese borde de lo Real"29. La "escritura" es pensada entonces como una juntura 30 entre lo Real y lo Simbólico, entre "Significante - Uno" (S1) -significante - letra - y el conjunto de los demás significantes (S2). Esto también esclarece la homología planteada más arriba entre "Significante - Uno" (S1) y "objeto a".

Por eso le interesa a Lacan resaltar que lo propio de la lógica como ciencia de lo Real es haber hecho de la "verdad" sólo un valor vacío. Ahora bien, esto sólo pudo suceder cuando se logró vaciar bastante de su sentido a las palabras para ser sustituidas por letras, y relata en relación a unos dísticos de Galileo donde éste dejó escritos algunos de sus descubrimientos de los cuerpos celestes: "la letra es en cierto modo inherente a ese pasaje a lo Real (...). Pero al dar pruebas de la fecha de la invención, da pruebas también de la invención misma; la invención es el escrito (...)"31. En este sentido, escribir algo es sinónimo de inventarlo, de materializarlo.

Lo escrito cobra entonces entidad y adviene en soporte, como mínimo en soporte de lo Inconsciente que, como dijimos, también es una "invención" - un saber que se inventa, no que se descubre-, y adquiere "entidad" a partir de que se lo escribe, que ahora es lo mismo que decir "a partir de que se lo inventa".

Recordemos que estas afirmaciones de Lacan refieren estrictamente a la experiencia analítica, si bien buscan apoyo y soporte, por ejemplo, en la lógica y sus procedimientos formales. "Históricamente es por unos pequeños pedazos de escritura que se ha entrado en lo Real, a saber que se ha cesado de imaginar, que la escritura de las pequeñas letras matemáticas, es eso lo que soporta lo Real (...). Me he dicho que la escritura, eso siempre debía tener algo que ver con la manera en que escribimos el nudo" 32 -leemos en el seminario «El sinthome»-.

"Es lo escrito lo que soporta (...), hay aquí una suerte de entidad de lo escrito (...) $[y]$ es en todo caso hoy lo mejor que encuentro para situar a ustedes la función

\footnotetext{
28 Lacan 1974-75, op. cit. (nota 11), p.136.

29 Ibídem.

30 Lacan 1998, op. cit. (nota 21), p. 95.

31 Lacan 1974-75, op. cit. (nota 11), p.137.

32 Lacan 2006, op. cit. (nota 7), pp. 38-41.
} 
de lo escrito, a lo cual nos ha introducido nuestra pregunta sobre la entidad de lo escrito (...) para situar el hecho de que se define ante todo por cierta función, por un lugar de borde" 33 - concluye Lacan-.

Decir ahora que "el inconsciente y la lógica son del orden de lo escrito" 34 cobra otra textura y significación: "es del lado de la escritura que se concentra aquello donde trato de interrogar acerca del inconsciente cuando digo que el inconsciente es algo en lo Real (...). Esa dimensión de saber toca en los bordes de lo Real (...), sólo la escritura soporta como tal a ese real"35. Pasemos ahora a la segunda definición de escritura.

2) La escritura con nudos borromeos: un hacer que da soporte al pensamiento.

Luego de haber explorado distintos objetos topológicos como la "banda de Moëbius", la botella de Klein, el cross-cap, etc., hacia el final de su enseñanza Lacan se interna en la exploración de la teoría de nudos, focalizando su pensamiento particularmente en el nudo borromeo utilizado como modelo del entrelazamiento de los tres registros. En esta acepción de escritura los nudos le permiten a Lacan escribir los hechos lógicos de lo Inconsciente tal como los despejábamos en el apartado anterior: lo que los nudos escriben son las condiciones del goce de cada ser hablante.

La escritura así entendida es "un hacer que da soporte al pensamiento (...). El «nudo bo» en cuestión cambia completamente el sentido de la escritura" 36 . Por otra parte, la escritura con nudos borromeos así entendida es Real, está por fuera del sentido: el nudo borromeo entonces "es también una escritura (...). El enigma de la escritura, de la escritura en tanto que puesta de plano, está aquí también al trazar lo que es esencialmente del orden de lo imaginable, o sea esa proyección en el espacio"37. Esta acepción es autónoma según Lacan de la tercera definición 38 .

Habiendo explorado más o menos en profundidad el concepto de "letra" y habiéndolo relacionado con lo que está por fuera del sentido, se evidencia que la escritura con nudos borromeos "viene de otra parte que del significante" 39 afirma Lacan.

\footnotetext{
33 Ibidem. Los corchetes nos pertenecen.

34 Véase la nota 11.

35 Lacan 1974-75, op. cit. (nota 11), p.137.

36 Lacan 2006, op. cit. (nota 7), p. 142.

37 Lacan 1974-75, op. cit. (nota 11), p. 122.

38 Lacan 2006, op. cit. (nota 7), p. 142.

39 Ibídem, pp. 143.
} 
Este nudo es un apoyo para el pensamiento, pero, curiosamente, para obtener algo de él, hay que escribirlo, mientras que, sólo con pensarlo, no es fácil representárselo y verlo funcionar, ni siquiera el más simple (...). Hay que escribirlo para ver cómo funciona. ${ }^{40}$

Como se podrá notar hay un estrecho parentesco entre la escritura con matemas y la escritura con nudos borromeos, ya que en algún sentido se puede sostener que los nudos borromeos aspiran a ser matemas, pero tampoco calzan perfectamente una con otra -en principio porque se trata de distintas topologías- y por eso cabe distinguirlas.

3) La escritura como cierta precipitación del significante, el acto de escribir sobre una superficie

Estrictamente hablando, sólo esta acepción alude al acto de escribir sobre una superficie y coincide con el sentido común de "escribir". Sigamos a Lacan en cómo él mismo separa esta acepción de la escritura de la anterior, de la escritura con nudos borromeos: "el nudo bo cambia completamente el sentido de la escritura. Confiere a dicha escritura una autonomía, tanto más notable cuanto que hay otra escritura, esa que resulta de lo que se podría llamar una precipitación del significante. En ella insistió Derrida, pero es completamente claro que yo le mostré el camino, como ya lo indica suficientemente que no he encontrado otra manera de sostener el significante más que con la escritura de $\mathrm{S}$ mayúscula. El significante es lo que queda. Pero lo que se modula en la voz no tiene nada que ver con la escritura"41.

Lacan siempre relacionó el concepto de "Significante" con el material fónico del lenguaje, con lo que se dice, no con lo que se escribe. Sostuvo que el psicoanálisis consiste en hablar, no en escribir. El psicoanálisis "pasa por cierto numero de enunciados. Nada dice que encamine a escribir (...). No está en absoluto decidido que con el psicoanálisis se llegue a escribir. Hablando con propiedad, esto supone una investigación de lo que significa escribir" 42.

En este contexto habría que como mínimo mencionar el debate Lacan - Derrida, especialmente enriquecedor para pensar la escritura como cierta precipitación del significante. Parte de esa disputa se juega en torno al problema de si la memoria es o no un sistema de inscripciones o una máquina de escritura, tema del cual Lacan se ocupó especialmente en el seminario 7 dedicado a la ética del psicoanálisis 43 y Derrida hizo otro tanto en su texto «Freud y la escena de la escritura»44. Allí pro-

40 Ibídem, pp. 142.

41 Ibídem.

42 Ibidem.

43 Lacan 2003, op. cit. (nota 13), pp. 57-88.

44 Derrida, J. «Freud y la escena de la escritura», en La escritura y la diferencia, Barcelona, Anthropos, 1989. 
pone pensar la metáfora del aparato psíquico freudiano como máquina de escritura - de traducción y transcripción de huellas mnémicas- basándose en textos como el «Proyecto de psicología para neurólogos» (1895), «Nota sobre la pizarra mágica» (1925), entre otros;

Lacan pareciera impugnar los desarrollos de Derrida en esa dirección diciendo: "uno se imagina que la memoria es algo que se imprime. Nada dice que esta metáfora sea válida. En su Entwurf («Proyecto de psicología para neurólogos»), Freud articula muy precisamente la impresión de lo que permanece, en la memoria. No es una razón, porque sabemos que los animales se acuerdan, para que sea lo mismo para el hombre ${ }^{45}$. Pero ése debate desborda y excede ampliamente los propósitos del presente ensayo.

Es también en el sentido de esta acepción pero abriendo la puerta también a una posible imbricación de las dos anteriores que Lacan afirma que "el decir deja desperdicios y, de él, sólo eso puede recogerse (...), ya sean desperdicios escritos o hablados" 46 . En esta vertiente de la escritura, la letra es un desecho47.

También es cierto que la escritura en tanto precipitación del significante en una superficie lleva implícito el problema del espacio y sus dimensiones, ya que "la escritura no se efectúa en un espacio menos especular que los otros. Incluso éste es el principio de ese liadísimo ejercicio llamado palíndromo"48, explica el autor.

Solidariamente a la problemática que articula escritura y espacialidad, Lacan sostiene que lo escrito en tanto materia, la materialidad de lo escrito, es algo que constituye "función - tiempo" y "función - superficie" simultáneamente ${ }^{49}$, pero no desarrolla estas ideas sino que solamente las menciona. Sin duda serán indicaciones para seguir investigando en relación a las funciones de la escritura en las psicosis.

\section{Una teoría materialista del lenguaje}

Por último, estas tres acepciones de "escritura" en Lacan -que como hemos visto se encuentran íntimamente entrelazadas- descansan sobre otro supuesto teórico relevante al cual denominaremos la Teoría Materialista del Lenguaje.

Dice Lacan: "lo mínimo que podéis concederme en cuanto a mi teoría del lenguaje es (...) que es materialista. El significante es la materia que se trasciende en el

45 Lacan, J., L'insu que sait de l'une bévue s'aile à mourre (1977-78) [seminario, libro 24], inédito, p. 50 .

46 Lacan, J., «Autocomentario. Intervención en el congreso de la Grande - Motte» (1973), Uno por Uno, Revista Mundial de Psicoanálisis Edición latinoamericana, 43 (Verano 96), Buenos Aires, Eolia, 1996, pp. 9-20.

47 Lacan, J., «Joyce el síntoma I» (1975), Uno por Uno, Revista Mundial de Psicoanálisis, Edición latinoamericana, 44 (Otoño 97), Buenos Aires, Eolia, 1997, p. 13.

48 Lacan 1974-75, op. cit. (nota 11), p. 36.

49 Lacan 1974-75, op. cit. (nota 11), pp. 137-138. 
lenguaje" 50 . En «El Atolondradicho» leemos: "no más materialista en eso que cualquiera que fuese sensato, yo o Marx, por ejemplo" 51 . Y también: "podría proponerles como fórmula de lo escrito el saber supuesto sujeto. Que haya algo que atestigua que una fórmula parecida pueda tener su función [Lacan hace referencia a la fórmula de la transferencia neurótica entendida como el Sujeto Supuesto Saber], es en todo caso hoy lo mejor que encuentro para situar ante ustedes la función de lo escrito, a lo cual nos ha introducido nuestra pregunta sobre la entidad de lo escrito (...) para situar el hecho de que se define ante todo por cierta función, por un lugar de borde (...). Esa materia de lo escrito, de lo escrito supuesto (...) merecería que se lo exprimiera un poco, para volver a nuestro objeto a fundamental" 52 .

En este parágrafo se dejan entrever ciertas relaciones entre esta concepción materialista y el "objeto a" por un lado; por el otro, hay una alusión a la fórmula de la transferencia pero invertida en sus términos: ellos aparecen en una secuencia diferente pero que da mucho que pensar si se trata de indagar las funciones de la escritura en las psicosis. Esta es una de las referencias que nos llevó a tomar en consideración la problemática de la transferencia en las psicosis, y en qué medida se convierte en una exploración ineludible si se pretende explorar en profundidad y seriamente las funciones de la escritura en las mismas.

En el Seminario 24 Lacan radicaliza estas nociones afirmando -en relación a lo que distingue a un significante de otro- que "todo lo que sostiene la diferencia de lo mismo y de lo otro, es que lo mismo sea lo mismo materialmente. La noción de materia es fundamental en cuanto que ella funda lo mismo. Todo lo que no está fundado sobre la materia es una estafa (...)" 53 . Es que "lo material se presenta a nosotros como consistente, quiero decir bajo la subsistencia del cuerpo, es decir de lo que es consistente, lo que se tiene junto a la manera de lo que se puede llamar un con, dicho de otro modo, una unidad" 54 . Aquí ubicamos una relación directa entre la materialidad del significante y la unidad corporal.

Lacan define entonces a lo inconsciente como un saber, y le otorga una materialidad: la del significante. Para el autor las cosas son consecuencias de los nombres, siendo esta la condición de posibilidad de la eficacia del psicoanálisis ${ }^{55}$.

\footnotetext{
${ }^{50}$ Lacan, J., «Respuesta a unos estudiantes de filosofía sobre el objeto del psicoanálisis» (1966), en El lugar del analista, Colombia, Escritos polémicos, s/f.

51 Lacan 1984, op. cit. (nota 9), p. 67.

52 Lacan 1974-75, op. cit. (nota 11), p. 138.

53 Lacan 1977-78, op. cit. (nota 44), p. 15.

54 Ibídem.

55 Ibidem, pp. 32-34.
} 


\section{4. ¿Qué es la hermenéutica textual para Ricoeur?}

\section{Hermenéutica filosófica y filosofia reflexiva}

Habiendo despejado algunas definiciones indispensables de cómo Lacan entiende el término "escritura", detengámonos ahora en la hermenéutica de Ricoeur para extraer de ella algunas nociones que nos serán de utilidad para explorar nuestro objeto de estudio. Continuaremos entonces realizando una descripción panorámica del concepto de hermenéutica en Ricoeur para luego detenernos con más detalle en la noción de "texto".

En varios escritos y artículos Ricoeur nos recuerda que el problema hermenéutico

se plantea ante todo dentro de los límites de la exégesis, es decir, en el marco de una disciplina que se propone comprender un texto, comprenderlo a partir de su intención, sobre la base de lo que quiere decir. Si la exégesis ha suscitado un problema hermenéutico, es decir, un problema de interpretación, es porque toda lectura de un texto, por más ligada que esté al quid, a «aquello en vista de lo cual» fue escrito, se hace siempre dentro de una comunidad, de una tradición o de una corriente de pensamiento viva, que desarrollan presupuestos y exigencias. ${ }^{56}$

A lo que Ricoeur apunta es al hecho de que, si bien ya en el Organon de

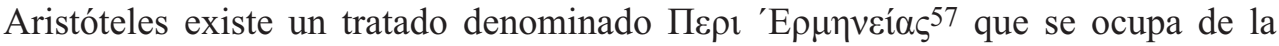
interpretación que a través del lenguaje se hace de lo pensado, lo que ya Aristóteles pone en juego es un problema más amplio: el vínculo entre interpretación y comprensión en el sentido amplio de la inteligencia de los signos, y esto es confirmado

por uno de los sentidos tradicionales de la palabra «hermenéutica» (...). En efecto, es notable que en Aristóteles el término no se restringe al de alegoría, sino que atañe a todo discurso significante; más aún, el discurso significante es hermeneia, es decir, «interpreta» la realidad, en la medida en que dice «algo de algo»; hay hermeneia porque la enunciación es una captura de lo real por medio de expresiones significantes, y no un extracto de supuestas impresiones provenientes de las cosas mismas. ${ }^{58}$

Pero es recién a finales del siglo XVIII y a principios del XIX que la hermenéutica se convierte en un problema filosófico con Schleiermacher y con Dilthey.

En su libro Freud: una interpretación de la cultura (1965) Ricoeur ya ubica la hermenéutica en el campo de la "reflexión", diciendo en este libro que "es la apropiación de nuestro esfuerzo por existir y de nuestro deseo de ser, a través de las

\footnotetext{
56 Ricoeur 2003, op. cit. (nota 1), p. 9.

57 Aristóteles, «Peri Hermeneias», en Tratados de lógica (Organon), México, Porrúa, 1979.

58 Ibidem, p. 10.
} 
obras que atestiguan ese esfuerzo y ese deseo; por eso la reflexión es más que una simple crítica del conocimiento y más aún que una simple crítica del juicio moral; antes de toda crítica del juicio, reflexiona sobre el acto de existir que desplegamos en el esfuerzo y en el deseo"59. Ubica la raíz última del problema hermenéutico "en esta conexión primitiva entre el acto de existir y los signos que desplegamos en nuestras obras; la reflexión debe convertirse en interpretación, porque no puedo captar este acto de existir más que en signos dispersos en el mundo"60.

En «Acerca de la interpretación» (1983), Ricoeur se ocupa de explicitar cuáles son los supuestos propios de la tradición filosófica a la cual pertenece: su tradición filosófica

corresponde a una filosofía reflexiva; se encuentra en la esfera de influencia de la fenomenología husserliana; pretende ser una variante hermenéutica de esa fenomenología (...). Una filosofía reflexiva es el modo de pensar procedente del cogito cartesiano, pasando por Kant y la filosofía poskantiana francesa (...) cuyo pensador más destacado ha sido a mi entender Jean Nabert. Los problemas filosóficos que una filosofía reflexiva considera más importantes se refieren a la posibilidad de la comprensión de uno mismo como sujeto de las operaciones cognoscitivas, volitivas, estimativas, etc.61

En este mismo artículo sostiene que la primera tarea de la hermenéutica es

buscar en el texto mismo, por una parte, la dinámica interna que rige la estructuración de la obra, y por otra, la capacidad de la obra para proyectarse fuera de sí misma y engendrar un mundo que sería verdaderamente la cosa del texto. Dinámica interna y proyección externa constituyen lo que llamo el trabajo del texto. La tarea de la hermenéutica consiste en reconstruir ese doble trabajo. 62

Profundicemos en qué consiste ese doble trabajo al cual alude Ricoeur. Por un lado, implica "reconstruir la dinámica interna del texto, y restituir la capacidad de la obra de proyectarse al exterior mediante la representación de un mundo habitable"63. A la tarea de reconstruir la dinámica interna del texto,

corresponden todos los análisis orientados a articular entre sí comprensión y explicación en el plano de lo que he llamado el sentido de la obra. Tanto en mis análisis del relato como en los de la metáfora, lucho en dos frentes: por una parte, rechazo el irracionalismo de la comprensión inmediata, concebida como una extensión al terreno de los tex-

\footnotetext{
59 Ricoeur, P., Freud: una interpretación de la cultura, México, 2009, p. 44.

60 Ibídem.

61 Ricoeur, P., «Acerca de la interpretación», en Del texto a la acción. Ensayos de hermenéutica II, Buenos Aires, Fondo de Cultura Económica, 2000, p. 28.

62 Ibidem, p. 34.

63 Ibídem.
} 
tos de la intropatía mediante la cual un sujeto se introduce en una consciencia extraña en la situación del cara a cara íntimo. Esta extensión indebida alimenta la ilusión romántica de un vínculo inmediato de congenialidad entre las dos subjetividades presentes en la obra, la del autor y la del lector. Pero rechazo con idéntica fuerza un racionalismo de la explicación que extendería al texto el análisis estructural de los sistemas de signos característicos no del discurso sino de la lengua. Esta extensión igualmente indebida engendra la ilusión positivista de una objetividad textual cerrada en sí misma e independiente de la subjetividad del autor y del lector. A estas dos actitudes unilaterales he opuesto la dialéctica de la comprensión y la explicación. Entiendo por comprensión la capacidad de continuar en uno mismo la labor de estructuración del texto, y por explicación la operación de segundo grado incorporada en esta comprensión y que consiste en la actualización de los códigos subyacentes en esta labor de estructuración que el lector acompaña. Este combate en dos frentes de una reducción de la comprensión a la intropatía y una reducción de la explicación a una combinatoria abstracta, me lleva a definir la interpretación mediante esta misma dialéctica de la comprensión y la explicación en el plano del sentido inmanente al texto. ${ }^{64}$

El gesto que quisiéramos retomar es que al plantear las cosas de esta manera, el horizonte de Ricoeur - quizás al igual que el de Lacan en alguna medida- fue preservar el diálogo entre filosofía y ciencias humanas, "diálogo que cortan, cada uno a su manera, los dos modos estrechos de la comprensión y la explicación que rechazo"65.

Tampoco podemos dejar de señalar que Ricoeur pretendió otorgarle a su hermenéutica una función crítica, de "arbitraje". Una hermenéutica filosófica comienza

por una investigación extensiva de las formas simbólicas y por un análisis comprensivo de las estructuras simbólicas; prosigue con una confrontación de los estilos hermenéuticos y con una crítica de los sistemas de interpretación, refiriendo la diversidad de los métodos hermenéuticos a la estructura de las teorías correspondientes. Con ello se prepara para ejercer su tarea más importante: llevar a cabo un verdadero arbitraje entre las pretensiones totalitarias de cada una de las interpretaciones. Al mostrar de qué manera cada método expresa la forma de una teoría, justifica a cada una en los límites de su propia circunscripción teórica. Tal es la función crítica de esta hermenéutica. 66

\section{¿Explicar o comprender? La operación de la lectura}

Habíamos dicho que es recién a finales del siglo XVIII y a principios del XIX que la hermenéutica se convierte en un problema filosófico con Schleiermacher y con Dilthey. En este punto es necesario ubicar el distanciamiento de Ricoeur de la "psicología de la comprensión” de Dilthey.

\footnotetext{
64 Ibidem, p. 35.

65 Ibídem.

66 Ricoeur 2003, op. cit. (nota 1), p. 19.
} 
Se sabe que ha sido el mismo Dilthey el inventor de la dualidad comprensión explicación. "En Dilthey, estas distinciones constituían una alternativa en la cuál un término debía excluir al otro; o bien se explica, a la manera del sabio naturalista, o bien se interpreta, a la manera del historiador" 67.

Pero la noción de "texto" tal como la concibe Ricoeur pretende una renovación de la dualidad conceptual antinómica explicación - comprensión. La comprensión para Dilthey es "ese traslado hacia el interior de un psiquismo ajeno" 68 y Ricoeur cita la definición completa: "Llamamos comprensión - dice en el famoso artículo de 1900 sobre el origen de la hermenéutica 69 - al proceso por el cual conocemos algo psíquico con la ayuda de signos sensibles que son su manifestación" (p. 320). La interpretación es una provincia particular de esta comprensión. Entre los signos del psiquismo ajeno, tenemos las "manifestaciones fijadas de una manera durable", los "testimonios humanos conservados por la escritura", los "monumentos escritos". La interpretación es así el arte de comprender aplicado a tales manifestaciones, a tales testimonios, a tales monumentos, cuyo carácter distintivo es la escritura"70.

Según Ricoeur la comprensión sería el fundamento, el conocimiento mediante signos del psiquismo ajeno, y la interpretación "aporta el grado de objetivación, gracias a la fijación y la conservación que la escritura confiere a los signos"71.

Sigue Ricoeur: "escuchemos a Dilthey comentando a Schleirmacher: "el fin último de la hermenéutica es comprender al autor mejor de lo que él se ha comprendido a sí mismo". He aquí la psicología de la comprensión. Pero veamos ahora la lógica de la interpretación: "es función de la hermenéutica establecer teóricamente contra la intrusión constante de lo arbitrario romántico y del subjetivismo escéptico en el dominio de la historia, la validez universal de la interpretación, base de toda certeza histórica" (p. 333). Así, la hermenéutica cumple los deseos de la comprensión al separarse de la inmediatez de la comprensión del otro, esto es, separándose de los valores dialogales. La comprensión quiere coincidir con el interior del autor, igualarse con él (sich gleichsetzen), reproducir (nachbilden) el proceso creador que ha engendrado la obra. Pero los signos de esta intención, de esta creación, sólo pueden buscarse en lo que Schleiermacher llama la forma exterior e interior de la obra, o incluso en la conexión, el encadenamiento (Zusammenhang), que hace de ella un todo organizado"72.

67 Ricoeur, P., «¿Qué es un texto?», en Del texto a la acción. Ensayos de hermenéutica II, Buenos Aires, Fondo de Cultura Económica, 2000, p. 132.

68 Ibídem.

69 Dilthey, W., «Origine et développement de l'hermeneutique» (1900), en Le monde de l'Esprit, I, París, 1947, citado por Ricoeur 2000, op. cit. (nota 58), p. 132.

70 Ricoeur 2000, op. cit. (nota 58), p. 133.

71 Ibidem.

72 Ibidem, p. 134. 
Lo que se esboza aquí es la necesidad -epistemológica quizás- de dejar de referir la interpretación a la comprensión del otro para rencauzarla en sus relaciones con la explicación; vía la pregunta por las condiciones de cientificidad de la interpretación, las fronteras entre la explicación como algo propio de las ciencias naturales y la comprensión como algo propio de las ciencias del espíritu se desdibuja nuevamente.

Entre la obra de Schleiermacher y la de Dilthey, lo que se ha acrecentado son las exigencias epistemológicas; el recorrido ricoeuriano por estos dos autores lo lleva a una formulación superadora de la antinomia explicación - comprensión, y esto se logra en Ricoeur postulando la noción de "texto" que desplegaremos más adelante.

Si se trata de "abandonar decididamente la referencia de la interpretación a la comprensión y dejar de hacer de la interpretación de los monumentos escritos un caso particular de la comprensión de los signos exteriores de un psiquismo interior"73, el "texto" mismo viene a situar una topología de la subjetividad, en principio porque el psiquismo deja de ser una interioridad que se descifra a partir de signos que se objetivan desde afuera, sino que pareciera emerger en el mismo movimiento o proceso que implica la operación de la lectura.

Esta temática alcanzará su despliegue máximo con la teoría de la triple mímesis trabajada por Ricoeur en Tiempo y Narración I. configuración del tiempo en el relato histórico, especialmente en lo referido al acto de lectura entendido como operación y como momento de un proceso, la "mímesis III". La tesis general de Tiempo y Narración I se compone y nutre básicamente de dos fuentes: por un lado, la discordancia de la experiencia de la temporalidad tal como la entiende San Agustín en Las confesiones y, por el otro, la teoría de la trama tomada de la Poética de Aristóteles.

Veo en las tramas que inventamos el medio privilegiado por el que re-configuramos nuestra experiencia temporal confusa, informe y, en el límite, muda: «¿Qué es, entonces, el tiempo? -pregunta Agustín-. Si nadie me lo pregunta, lo sé; si quiero explicárselo a quién me lo pregunta, ya no lo sé». La función referencial de la trama reside precisamente en la capacidad que tiene la ficción de re-figurar esta experiencia temporal víctima de las aporías de la especulación filosófica. ${ }^{74}$

El concepto de "mímesis III", alude precisamente al punto de intersección entre el mundo del texto y el mundo del lector. El acto de leer acompaña la configuración de la trama y actualiza la capacidad del texto para ser leído. Como dice Ricoeur,

\footnotetext{
73 Ibídem.

74 Ricoeur, P., Tiempo y narración I. Configuración del tiempo en el relato histórico, México, Siglo XXI, 2007, p. 34.
} 
"estos rasgos contribuyen particularmente a superar el prejuicio que opone un «dentro» y un «fuera» del texto. En efecto, esta oposición está estrechamente ligada a una concepción estática y cerrada de la estructura del texto solo. La noción de la actividad estructurante, visible en la operación de la construcción de la trama, trasciende esta oposición"75.

\section{La noción de "Texto": la fijación por la escritura}

"Llamamos texto a todo discurso fijado por la escritura. Según esta definición, la fijación por la escritura es constitutiva del texto mismo"76. Haciendo referencia a la anterioridad tanto psicológica como sociológica del habla en relación con la escritura, Ricoeur sostiene que "lo que fija la escritura es, pues, un discurso que se habría podido decir (...). La fijación por la escritura se produce en el lugar mismo del habla, es decir, en donde el habla habría podido aparecer. Nos podemos preguntar si el texto no es realmente texto cuando no se limita a transcribir un habla anterior, sino cuando inscribe directamente en la letra lo que quiere decir el discurso"77. Al igual que en Tiempo y narración I, Ricoeur piensa en las funciones de la lectura como una operación inseparable de la noción de "texto". "Lo que podría dar peso a esta idea de una relación directa entre el querer decir del enunciado y la escritura, es la función de la lectura respecto de la escritura"78 -refiere unas líneas más adelante-.

En relación a las diferencias entre el acto de la lectura y el acto del diálogo, el autor sentencia que

la escritura es una realización comparable al habla (...), una realización que toma su lugar y que de alguna manera la intercepta. Por esta razón podemos decir que lo que llega a la escritura es el discurso en tanto intención de decir, y que la escritura es una inscripción directa de esta intención, aun cuando, histórica y psicológicamente, la escritura comenzó por transcribir gráficamente los signos del habla. Esta liberación de la escritura que la pone en el lugar del habla es el acto de nacimiento del texto. ${ }^{79}$

Ahora bien, hay un problema del cual Ricoeur se ocupa tanto en relación al "texto" como en relación a la "construcción de la trama" -como veíamos en Tiempo y Narración I-; es el problema de la función referencial del texto. La apuesta de Ricoeur es que la escritura no sólo instala una relación perturbadora en relación al habla -interceptándola- sino que provoca un "trastorno que alcanza a la relación referencial del lenguaje con el mundo cuando el texto toma el lugar del habla" 80 .

\footnotetext{
75 Ibídem, p. 147.

76 Ricoeur 2000, op. cit. (nota 67), p. 127.

77 Ibidem, p. 128.

78 Ibídem.

79 Ibidem, p. 129.

80 Ibídem.
} 
Cuando un hablante se dirige a otro, dice algo sobre algo, y aquello sobre lo que se está hablando sería el referente de su discurso. La unidad discursiva mínima en la cual está presente esta función referencial es la oración. Según Ricoeur, esta función referencial viene a contrabalancear otra característica inherente al lenguaje que es la de separar los signos de las cosas. Mediante la función referencial, "el lenguaje «reintegra al universo» (...) estos signos que la función simbólica, en su nacimiento, hicieron ausentes en las cosas. Todo discurso se encuentra así vinculado, en alguna medida, al mundo. Pues si no se habla del mundo ¿de qué hablaríamos?"81. En este punto Ricoeur vuelve a separar lo que ocurre con el acto de lectura y el acto del diálogo, ya que en el diálogo -en la presencia mutua de los hablantes- la relación referencial se produce por una multiplicidad de elementos, por ejemplo la situación, el ambiente, etc. Pero la realidad a la cual remite el discurso, es esta realidad que puede ser mostrada en torno -dice Ricoeur-a los hablantes, "en torno de la propia instancia de discurso" 82 .

El lenguaje viene equipado con un arsenal de elementos que aseguran este anclaje:

los demostrativos, los adverbios de tiempo y de lugar, los pronombres personales, los tiempos del verbo, y en general todos los indicadores deícticos u ostensivos sirven para anclar el discurso en la realidad circunstancial que rodea a la instancia de discurso. Así, en el habla viva, el sentido ideal de lo que se dice se inclina hacia la referencia real, hacia aquello sobre lo cual se habla. En el límite, esta referencia real tiende a confundirse con una designación ostensiva donde el habla se une al gesto de mostrar, de hacer ver. El sentido muere en la referencia y ésta en la mostración. 83

Ahora bien, no ocurre lo mismo con el texto. Es este movimiento mismo que va de la referencia a la mostración lo que se encuentra interceptado -al mismo tiempo que el texto no permite el "diálogo"-. Aquí entra en juego nuevamente la operación de la lectura: la tarea de la lectura como interpretación será precisamente "efectuar la referencia" 84 . Donde la referencia queda diferida -no abolida- el texto se desprende al menos parcialmente del mundo, queda "en el aire", fuera del mundo. "Tal es la conmoción que afecta al discurso mismo, cuando el movimiento de la referencia hacia la mostración se encuentra interceptado por el texto; las palabras dejan de desaparecer ante las cosas; las palabras escritas devienen palabras por sí mismas"85.

En Tiempo y narración I este problema es mencionado y retomado luego de haber sido extensamente razonado en La metáfora viva ${ }^{86}$, donde era designado

\footnotetext{
81 Ibídem, p. 130.

82 Ibídem.

83 Ibídem.

84 Ibídem.

85 Ibídem.

86 Ricoeur, P., La metáfora viva, Madrid, Cristiandad, 1980.
} 
como "referencia metafórica". El concepto hace referencia a todos los usos no descriptivos del lenguaje, es decir, a todos los textos poéticos, sean líricos o narrativos.

La referencia metafórica (...) consiste en que la supresión de la referencia descriptiva -que, en una primera aproximación, reenvía el lenguaje a sí mismo- se revela, en una segunda aproximación, como la condición negativa para que sea liberado un poder más radical de referencia a aspectos de nuestro ser - en - el - mundo que no se pueden decir de manera directa. Estos aspectos son apuntados, de modo indirecto, pero positivamente afirmativo, gracias a la nueva pertinencia que el enunciado metafórico establece en el plano del sentido, sobre las ruinas del sentido literal abolido por su propia impertinencia. 87

La argumentación aquí adquiere alcance ontológico, ya que la referencia metafórica implica un "ser - como" y una dimensión ontológica propia abierta por las obras de ficción en tanto que amplían nuestros horizontes de existencia. "El postulado subyacente en este reconocimiento de la función de refiguración de la obra poética en general es el de una hermenéutica que mira no tanto a restituir las intenciones del autor detrás del texto como a explicitar el movimiento por el que el texto despliega un mundo, en cierto modo, delante de sí mismo"88.

Estos desarrollos inciden a su vez en la relación del "texto" con las subjetividades del autor y del lector.

Creemos saber lo que es el autor de un texto, porque se deriva la idea de la de hablante; el sujeto del habla, dice Benveniste, es el que se designa a sí mismo diciendo «yo». Cuando el texto toma el lugar de la palabra, ya no hay locutor propiamente hablando, al menos en el sentido de una autodesignación inmediata y directa del que habla en la instancia de discurso. Esta proximidad del sujeto hablante con su propia palabra es sustituida por una relación compleja del autor con el texto que permite decir que el autor es instituido por el texto, que él mismo se sostiene en el espacio de significado trazado e inscripto por la escritura. El texto es el lugar mismo donde el autor adviene. ${ }^{89}$

\section{Algunas conclusiones: pertinencia y ventajas metodológicas de los conceptos de Ricoeur para explorar las funciones de la escritura en las psicosis según Lacan}

La hipótesis que quisiéramos formular aquí es que, cuando se trata de pensar imbricadamente la noción de "texto" en Ricoeur y la de "escritura" en Lacan, ambas doctrinas se enriquecen a la hora de reflexionar sobre las funciones de la

87 Ricoeur 2007, op. cit. (nota 73), p. 152.

88 Ibídem, p. 153.

89 Ricoeur 2000, op. cit. (nota 66), p. 131. 
escritura en las psicosis, y este marco epistemológico otorga al psicoanálisis mayor precisión metodológica.

Una primera aproximación podría sugerir que la noción de "texto" en Ricoeur quedaría completamente ubicada dentro del campo de la "escritura" entendida lacanianamente como una "precipitación del significante", aquello que delimitábamos en la tercera acepción del término "escritura". Pero para Ricoeur la escritura "no constituye de ninguna manera la problemática única del texto"90 ni tampoco pueden identificarse pura y simplemente "texto" y "escritura", y el argumento principal es que "no es la escritura como tal la que suscita un problema hermenéutico, sino la dialéctica entre el habla y la escritura" 91 .

Metodológicamente hablando, sería interesante tener la ocasión de abordar los escritos psicóticos en tanto "textos" en sentido ricoeuriano, estableciendo nuestras hipótesis psicoanalíticas a partir de ese movimiento de vaivén entre lo escrito y lo que el sujeto psicótico diga -hablando- de aquello que escribió; es aquí mismo -como decía Ricoeur- donde se suscita el problema hermenéutico.

Como adelantábamos en la introducción, no pretendemos dejar de lado el análisis de los textos de Artaud, Hölderlin o Joyce -por citar algunos personajes relevantes-, sino que pretendemos cotejarlos con una metodología clara y pertinente al objeto de estudio en cuestión, sin dejar de lado exigencias metodológicas y epistemológicas, ya que en ciencias humanas "la doctrina es método"92.

Cierto es que si pretendemos abordar y estudiar lo que los sujetos psicóticos escriben, la noción de "texto" de Ricoeur definida como un discurso fijado por la escritura, que inscribe directamente en la letra lo que quiere decir el discurso, que tiene cierto efecto "liberador" en relación al habla, que conmociona la función referencial del habla -donde la tarea de la lectura como interpretación será precisamente "efectuar la referencia" y producir que las palabras dejen de desaparecer ante las cosas y permitir que las palabras escritas devengan palabras por sí mismas-, se nos aparece como el más pertinente ya que incluye el concepto de "escritura" de Lacan entendido como "cierta precipitación del significante", pero no lo reduce exclusivamente a ello.

Esto tiene la ventaja teórica de permitir explorar si acaso la escritura en las psicosis - cuando tiene efectos de estabilización- no tendrá la función de hacer funcionar en simultáneo las tres acepciones de escritura, si por ello entendemos la posibilidad de "existir" en el espacio abierto por los textos y a través del acto de escribir (en tanto precipitación del significante) alcanzar la inscripción de un goce Inconsciente.

\footnotetext{
90 Ricoeur 2000, op. cit. (nota 5), p. 96.

91 Ibídem.

92 Ricoeur, P., «Lo consciente y lo inconsciente», en El conflicto de las interpretaciones. Ensayos de hermenéutica, Buenos Aires, Fondo de Cultura Económica, 2003, p. 96.
} 
Esto implicaría trazar una "escritura" de otro orden, una escritura - inscripción psíquica del goce que, en ausencia de lo Inconsciente como aquello que en las neurosis cifra el goce -permitiendo ser luego "descifrado" por la intervención analítica-, permite en el "texto" -vía la escritura- suplir esta función, suplir la función de lo Inconsciente en el "texto".

Técnicamente hablando, no habría "Inconsciente" en las psicosis, y esto lleva a muchos sujetos psicóticos a buscar en la escritura algo que homologue a las funciones de cifrado del goce.

Casualmente las psicosis perturban la posibilidad de tomar la palabra en primera persona diciendo "Yo" desde un soporte Simbólico y no meramente Imaginario; se trata de un fenómeno que trastoca la posibilidad de instituir un Sujeto que advenga entre los significantes de una cadena cualquiera; tanto es así que Lacan indicó buscar el efecto de la forclusión del Nombre - del - Padre tras los rastros de una deixis imposible que se presenta como "cadena rota", produciendo que algunos significantes se presenten en lo Real -léase aquí "deteniendo el deslizamiento de la significación"-, produciendo una inequívoca alteración de la economía de la significación en el discurso que Lacan denominó "autorreferencia".

Se entiende por "autorreferencia" una suerte de pliegue sobre sí, de detención de la remisión de la significación, que Lacan denominó también "neologismo". Lo que define al neologismo es exactamente eso, que se trata de una significación que remite fundamentalmente a sí misma -a la significación en cuanto tal-, produciendo un peso y una inercia en el discurso que hace que las palabras pesen, que caigan como una "plomada en la red del discurso del sujeto"93.

En relación a una paciente psicótica que Lacan estudia en una presentación de enfermos, ubica cómo la designación del sujeto hablante - el decir "yo" [je]- queda en suspenso cuando ella habla y así demuestra que en la psicosis paranoica la cadena significante se interrumpe en el lugar exacto donde debería aparecer la función del shifter, y los pronombres personales son para Lacan su ejemplo eminente ${ }^{94}$.

La radicalización de estas consideraciones lo llevarán a Lacan a sostener que el psicótico es el paradigma de un ser habitado por el lenguaje, parasitado por el lenguaje como todo "ser - hablante", pero sin los recursos del neurótico -más específicamente el fantasma $[(\$ \diamond a)]$ - para velar dicha intrusión, dicho parasitismo del lenguaje.

En este sentido los psicóticos en general vendrían a ser los máximos exponentes de la afirmación heideggeriana según la cual "el lenguaje es la casa del ser", y de cómo es el lenguaje el que rige nuestro Dasein ${ }^{95}$, tesis que Lacan también tomó

\footnotetext{
93 Lacan, J., Las psicosis [seminario, libro 3], Buenos Aires, Paidós, 2002, pp. 52-53.

94 Lacan, J. «De una cuestión preliminar a todo tratamiento posible de la psicosis» (1957-58), en Escritos 2, Buenos Aires, Siglo XXI, 1987, p. 517.

95 Heidegger 2000, op. cit. (nota 2).
} 
pero no solamente de Heidegger, sino desde la práctica clínica de la mano de su maestro en psiquiatría G. De Clérambault y en relación al fenómeno clínico denominado "automatismo mental" 96 . Tal es así que en el seminario 24 Lacan afirma que el automatismo mental es normal ${ }^{17}$-siguiendo irónica y provocativamente estas consideraciones-.

¿Será entonces que el "texto" le permite al psicótico instituirse como agente del discurso sin tener que apelar a los shifters, evitando la posibilidad de que se le pregunte "¿Quién habla"?

Aquí la fijación por la escritura podría prestar grandes ventajas; recordemos que el surgimiento de la teoría ricoeuriana del "texto" parte de la lingüística oracional que siguiendo a Benveniste toma como la unidad básica del discurso a la oración. Del lado de la lingüística de De Saussure, a "la lengua" no se le puede preguntar "¿quién habla?” porque la lengua no tiene sujeto. Esto permitiría reconsiderar tanto la noción lacaniana de que el psicótico es parasitado abiertamente por el lenguaje (si bien en la terminología lacaniana sería más preciso decir por "lalangue", el "enjambre de Significantes - Uno"98) como la posible función básica del "texto" para el psicótico.

Quisiéramos sugerir que esta función básica está estrechamente relacionada con cómo "la escritura convierte al texto en algo autónomo"99, pero no solamente autónomo respecto de las intenciones del autor, sino que también lo hace autónomo en relación al acto de tomar la palabra al hablar.

La escritura permite así un distanciamiento aún mayor que el habla respecto de la función primordial del lenguaje (esta característica inherente al lenguaje que es la de separar los signos de las cosas). El discurso escrito

se crea un público que se extiende virtualmente a cualquiera que sepa leer. La escritura encuentra aquí su mayor efecto: la liberación de la cosa escrita respecto de la condición dialogal del discurso (...). Esta autonomía del texto tiene una primera consecuencia hermenéutica importante: el distanciamiento no es el producto de la metodología y, en este sentido, algo agregado o parasitario; es constitutivo del fenómeno del texto como escritura. 100

La forclusión del Nombre - del - padre lleva espontáneamente a escribir más que a hablar ya que, entre otras ventajas, permite eludir el acto de tener que ocupar el lugar del agente del discurso y así permite sostener un discurso pero sin asumir

\footnotetext{
96 De Clérambault, G. Automatismo mental. Paranoia. Presentación de P. Bercherie, Buenos Aires, Editorial Polemos, 1995.

97 Lacan 1977-78, op. cit. (nota 45), p. 51.

98 Lacan 1998, op. cit. (nota 22).

99 Ricoeur 2000, op. cit (nota 5), p. 104.

100 Ibídem, p. 105.
} 
la posición de sujeto de la enunciación, aquello que los shifters y su función nos mostraban como lugar imposible para el sujeto de la psicosis.

Evoquemos aquí la ahora familiar cita de Ricoeur:

creemos saber lo que es el autor de un texto, porque se deriva la idea de la de hablante; el sujeto del habla, dice Benveniste, es el que se designa a sí mismo diciendo «yo». Cuando el texto toma el lugar de la palabra, ya no hay locutor propiamente hablando, al menos en el sentido de una autodesignación inmediata y directa del que habla en la instancia de discurso. Esta proximidad del sujeto hablante con su propia palabra es sustituida por una relación compleja del autor con el texto que permite decir que el autor es instituido por el texto, que él mismo se sostiene en el espacio de significado trazado e inscripto por la escritura. El texto es el lugar mismo donde el autor adviene.101

¿Qué sucede si retenemos la noción ricoeuriana de que "el texto tiene referencia; ésta será precisamente la tarea de la lectura como interpretación: efectuar la referencia" 102 pero le agregamos que para muchos psicóticos lo que cumple una función de estabilización es el acto de lectura de sus propios escritos permitiendo la apropiación de algunos elementos expulsados de lo Simbólico por la forclusión del Nombre - del - Padre? Aquí las letras son desechos, pero también huellas que pueden leerse, nutriendo la comprensión de sí mismo.

Retomemos ahora en este contexto la problemática de la función referencial del texto para explorarla en el campo de las psicosis. Hablábamos más arriba de cómo la "autorreferencia" permitía distinguir la rúbrica del delirio, y dijimos que se trata de un fenómeno discursivo asequible en el campo de la significación. Lo que Lacan utiliza como el signo patognomónico del delirio, ¿no es precisamente un problema referencial?

La autorreferencia exhibe obscenamente la falla estructural con la cual debe lidiar el psicótico: falla la función característica e inherente del lenguaje que consiste en separar los signos de las cosas, y esto permite esclarecer por qué el psicótico padece la significación en sí misma, la significación en cuanto tal, correlato que da cuenta de que el significante se le presenta en el registro Real, rompiendo las cadenas Simbólicas. Del lado de la esquizofrenia, podríamos ubicar algo que Freud pesquisó con claridad: cómo al esquizofrénico las palabras se le vuelven cosas ${ }^{103}$.

Si entendemos la forclusión del Nombre - del-Padre como un mecanismo que, entre otras cosas, coagula la significación y menoscaba la posibilidad de un Sujeto de representarse entre los significantes -y en este sentido se ve imposibilitado de "existir" en lo Simbólico-, la escritura puede liberar y expandir el encorsetamiento

\footnotetext{
101 Véase la nota 89.

102 Véase la nota 84.

103 Freud, S., «Complemento metapsicológico a la doctrina de los sueños» (1917), en Obras Completas, tomo XIV, Buenos Aires, Amorrortu, 2000, pp. 227-228.
} 
significante padecido por los sujetos psicóticos al permitirles "instituirse en el texto", es decir, advenir en tanto Sujeto - existir- en el texto mismo. Aquí la lectura lacaniana de las funciones de la escritura en Joyce, por ejemplo, habría sido absolutamente convergente con la que se podría realizar desde la noción ricoeuriana del "texto".

Habría que agregar que si estas hipótesis son sustentables, la obra misma adviene al lugar del Nombre - del-Padre -cumpliendo sus funciones-, en el sentido de que este concepto funciona en la subjetividad como el lugar del "referente" en la semántica de Frege 104; pero vamos a contradecir abiertamente a Frege o más bien a ubicar cómo un psicótico que logra estabilizarse escribiendo lo hace subvirtiendo las fórmulas fregeanas. Frege sostuvo que "para la poesía basta con el sentido, con el pensamiento sin referencia, sin valor veritativo"105. Quizás algunos psicóticos logran -en el "texto"- que su poesía sea elevada al lugar del referente, y logran otorgarle un valor de verdad ontológico al ser los textos mismos los que lo instituyen como Sujeto. Aquí dicho referente no se trata de un objeto de la realidad, salvo que consideremos al texto mismo como "objeto", o a la escritura misma -al acto de escribir- como "objeto", y siempre y cuando se aclare el viraje paradigmático: no podría sostenerse este aserto en un marco epistemológico positivista como el fregeano. Queda abierta la pregunta de si se lo puede hacer desde uno hermenéutico, o desde uno psicoanalítico con un injerto hermenéutico.

No sabemos si Ricoeur pensó o no en detenerse en la escritura en las psicosis, pero sin duda sería fructífero reanimar desde esta perspectiva el problema ontológico de la referencia106 que tanto le interesaba.

Por último, quisiéramos destacar algunas afinidades conceptuales relevantes entre ambos autores fundamentales para la solicitada coherencia metodológica. Haciendo una lectura fragmentaria pero transversal de algunas obras de Ricoeur y otras de Lacan, podemos arribar a la conclusión de que ambos autores han concebido una subjetividad no sustancial.

En Lacan, se trata de concebir un Sujeto que adviene como efecto de significación entre los Significantes, siendo indisociables su concepción del Sujeto y su concepción del Significante, abriendo la investigación a la topología que trata de pensar la subjetividad a partir de una estricta metodología que se mantiene en el campo del lenguaje y de lo dicho. De ahí la necesidad de seguir explorando cómo otorgarle validez a muchos conceptos esgrimidos en el campo de la escritura y que conciernen a una lógica subjetiva psicótica.

104 Frege, G., «Sobre sentido y referencia», en Estudios sobre semántica, Madrid, Hyspamérica, 1985, p. 54.

105 Frege, G., «Consideraciones sobre sentido y referencia», en Estudios sobre semántica, Madrid, Hyspamérica, 1985, p. 98.

106 Ricoeur 2007, op. cit. (nota 74), pp. 148-155. 
En Ricoeur, la noción de la actividad estructurante, visible en la operación de construcción de la trama ataca el prejuicio de un "dentro" y un "fuera" del texto. Por otra parte,

su concepción de la interpretación permite una defensa adecuada de una nueva noción de subjetividad no sustancial, al incorporar para su tematización la transformación posible que alcanza para su autocomprensión un sujeto despojado ya de toda pretensión de dominio del sentido. La interpretación (...) no es el acto de un sujeto que en dominio de su propio ser en el mundo proyecta el a priori de su autocomprensión en el texto y lo lee en el texto, sino el proceso por el cual la revelación de nuevos modos de ser da al sujeto una nueva capacidad para conocerse a sí mismo. 107

Quedan pendientes para futuros ensayos la ampliación y profundización de estas nuevas perspectivas y direcciones de análisis para pensar las funciones de la escritura en las psicosis a partir de un psicoanálisis lacaniano que lleva en su seno un injerto hermenéutico.

107 Gende, C. E., Lenguaje e interpretación en Paul Ricoeur. Su teoría del texto como crítica a los reduccionismos de Umberto Eco y Jacques Derrida, Buenos Aires, Prometeo, 2004, p. 25. 